\title{
Połączenia glikokortykosteroidu
} $z$ długo działającym $\beta_{2}$-mimetykiem w inhalatorze ciśnieniowym dozującym - jakie, komu, kiedy?

\section{Combination of a glucocorticosteroid with a long-acting $\beta_{2}$-mimetics in a pressurized metered dose inhaler - what, who, when?}

Andrzej Emeryk ${ }^{1}$, Kamil Janeczek', ${ }^{1}$ Tomasz R. Sosnowski ${ }^{3}$, Justyna Emeryk-Maksymiuk ${ }^{2}$ ${ }^{1}$ Klinika Chorób Płuc i Reumatologii Dziecięcej, Uniwersytet Medyczny w Lublinie Kierownik Kliniki: prof. dr hab. n. med. Andrzej Emeryk ${ }^{2}$ Katedra i Zakład Pielęgniarstwa Internistycznego, Uniwersytet Medyczny w Lublinie Kierownik: dr hab. n. med. Agnieszka Zwolak

${ }^{3}$ Katedra Inżynierii Procesów Zintegrowanych, Wydział Inżynierii Chemicznej i Procesowej, Politechnika Warszawska Kierownik: prof. dr hab. inż. Tomasz R. Sosnowski

\begin{abstract}
Streszczenie:
W pracy o charakterze przeglądowym przedstawiono dane dotyczące inhalatorów ciśnieniowych dozujących. Omówiono zasady działania i formulacje leków w tego typu inhalatorach. Pokazano różnice w charakterystyce chmur aerozolowych i wielkości depozycji płucnej wybranych leków inhalowanych z inhalatorów ciśnieniowych dozujących. Szczególny nacisk położono na inhalatory ciśnieniowe dozujące zawierające połączenia glikokortykosteroidu wziewnego z długo działającym $\beta_{2}$-mimetykiem. Zwrócono uwagę na konieczność stosowania odpowiednich komór inhalacyjnych podczas inhalacji leków z inhalatora ciśnieniowego dozującego. Porównano efektywność i koszty terapii z inhalatorów ciśnieniowych dozujących vs inne urządzenia inhalacyjne (inhalatory suchego proszku, nebulizatory). Wyszzzególniono sytuacje kliniczne, w których inhalator ciśnieniowy dozujący może być pierwszym wyborem spośród innych inhalatorów u chorych na astmę lub przewlekłą obturacyjną chorobę płuc.
\end{abstract}

\begin{abstract}
:
The review paper presents data on pressurized metered dose inhalers. The principles of action and drug formulation in pressurized metered dose inhalers are discussed. The differences in the characteristics of aerosol clouds and the amount of pulmonary deposition of selected drugs inhaled with pressurized metered dose inhalers are shown. Particular emphasis was placed on pressurized metered dose inhalers containing combinations of an inhaled glucocorticosteroid with a long-acting $\beta_{2}$-agonist. The necessity to use appropriate inhalation chambers during pressurized metered dose inhalers inhalation was emphasized. The effectiveness and costs of therapy were compared with pressurized metered dose inhalers vs. other inhalation devices (dry powder inhalers, nebulizers). Clinical situations where pressurized metered dose inhalers may be the first choice among other inhalers in patients with asthma or chronic obstructive pulmonary disease are listed.
\end{abstract}

Słowa kluczowe: inhalator ciśnieniowy dozujący, propionian flutykazonu, salmeterol, chmura aerozolowa, astma, dzieci, dorośli Key words: pressurized metered dose inhaler, fluticasone propionate, salmeterol, aerosol cloud, asthma, children, adults 


\section{Inhalatory ciśnieniowe dozujące}

Inhalatory ciśnieniowe dozujące (pMDI, pressurized metered dose inhalers) należą do grupy urządzeń inhalacyjnych (inhalatorów) najczęściej stosowanych w codziennej praktyce lekarskiej. Obecnie w kraju leki z tych urządzeń stanowią ok. 45\% leków sprzedawanych spośród wszystkich inhalatorów indywidualnych [1]. Pozostałe grupy inhalatorów to inhalatory suchego proszku (DPI, dry powder inhaler), nebulizatory oraz inhalator odmierzonej dawki leku w płynie (ryc. 1). Inhalatory ciśnieniowe dozujące są znane od prawie 65 lat $[2,3]$. Chociaż w ostatnich latach więcej publikacji dotyczy DPI czy nebulizacji, to pMDI są nadal bardzo ważną grupą urządzeń inhalacyjnych stosowaną z lekami do terapii astmy i przewlekłej obturacyjnej choroby płuc (POChP). Zasady ich działania pozostają praktycznie niezmienne od lat 50. ubiegłego wieku do dzisiaj. Wytworzenie aerozolu polega na gwałtownej dekompresji ciekłego nośnika, tzw. propelentu, zawierającego lek (w formie rozpuszczonej lub zawieszonej) podczas przejścia przez zawór odcinający zawartość pojemnika ciśnieniowego od otoczenia. Następnie w wyniku odparowania nośnika wielkość kropel ulega zmniejszeniu z 20-30 $\mu \mathrm{m}$ do kilku mikrometrów, a więc stają się one odpowiednie do depozycji także w dolnych drogach oddechowych [4]. Zmienia się co pewien czas rodzaj propelentu - obecnie dominują hydrofluoroalkany (HFA, hydrofluoroalkane) 134a i 227a $[5,6]$. Trwają prace nad nośnikami o mniejszym śladzie węglowym, jak np. HFA 152a, oraz lepszymi surfaktantami czy rozpuszczalnikami [7].

Ze względu na sposób inhalowania pMDIs dzieli się na dwie duże grupy [5, 9]:
- pMDI klasyczne - wymagające koordynacji pomiędzy odmierzeniem i uwolnieniem dawki leku (tj. naciśnięciem pojemnika) a wdechem chorego (jeden typ urządzenia, bardzo dużo leków)

- pMDI aktywowane wdechem (pMDI-BA, pressurized metered dose inhalers - breath actuated) - niewymagające takiej koordynacji, ponieważ dawka leku jest automatycznie uwalniana po wykonaniu odpowiednio głębokiego i szybkiego wdechu przez pacjenta (kilka typów urządzeń, kilka leków).

Ze względu na formulację leków zawartych w pMDI można wyróżnić dwie grupy, w zależności od rozpuszczalności substancji czynnej w nośniku [7]:

- roztwory - substancja lecznicza jest rozpuszczona w płynnym propelencie

- zawiesiny - substancja lecznicza w formie mikrocząstek jest zawieszona w płynnym propelencie za pomocą nieaktywnych leczniczo dodatków.

W każdej z dwóch zasadniczych grup można wyróżnić po kilka różnych formulacji (ryc. 2).

W pMDI zawierających glikokortykosteroid wziewny (wGKS) i długo działający $\beta_{2}$-mimetyk (LABA, long-acting $\beta_{2}$-agonist) w formie zawiesiny w HFA występują następujące formulacje [11-13]:

- zawiesina bez dodatków - np. propionian flutykazonu (PF) i salmeterol (SALM) w preparacie Advair $^{\circledR}$ HFA 134a

- zawiesina z dodatkiem polimerów rozpuszczalnych w HFA, takich jak PEG i PVP (jako stabilizatory zawiesiny) - np. budezonid (BUD) i formoterol (FORM) w preparacie Symbicort ${ }^{\circledR}$ HFA 227a

Rycina 1. Podziat metod i urządzeń inhalacyjnych stosowanych w aerozoloterapii schorzeń dróg oddechowych (na podstawie [8]).

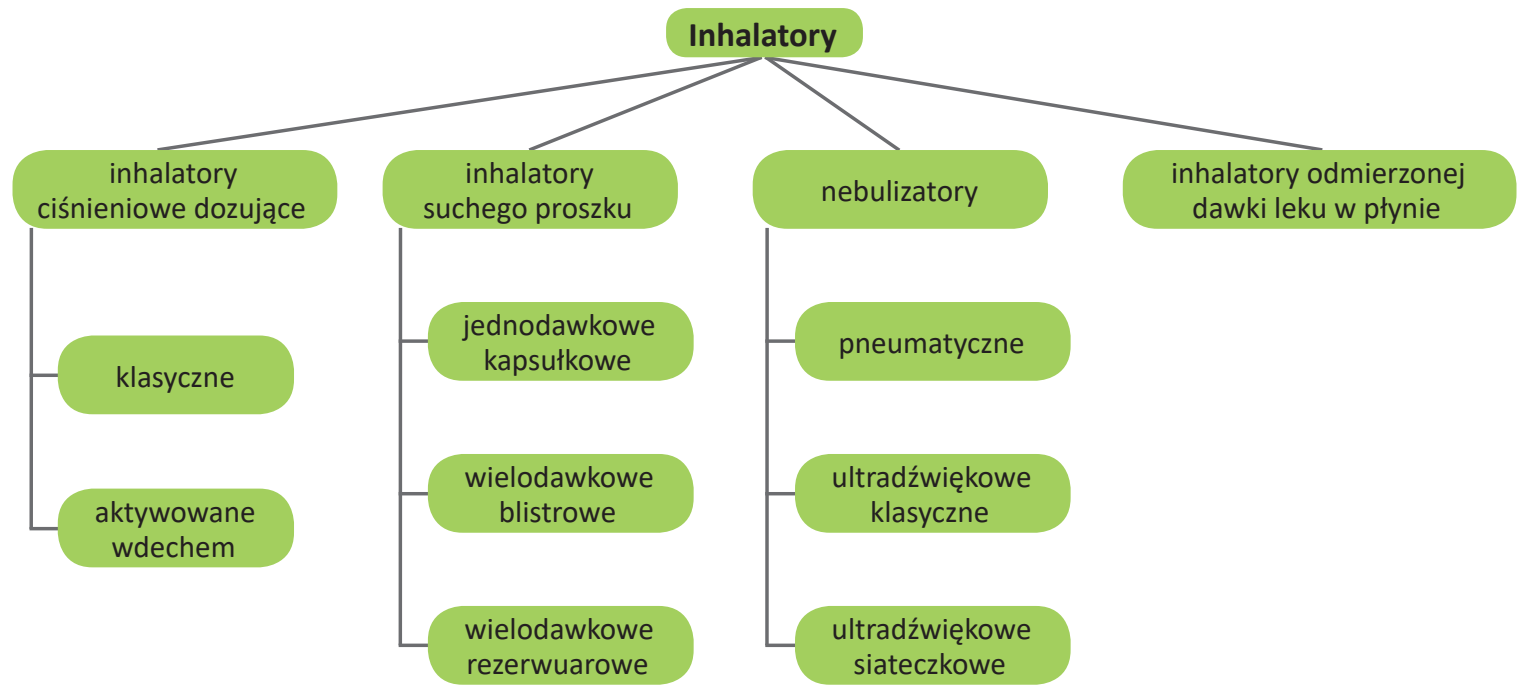


Rycina 2. Podziat leków w pMDI ze względu na rodzaj formulacji. QVAR - is a registered trademark of IVAX LLC, a member of the TEVA Group [10].

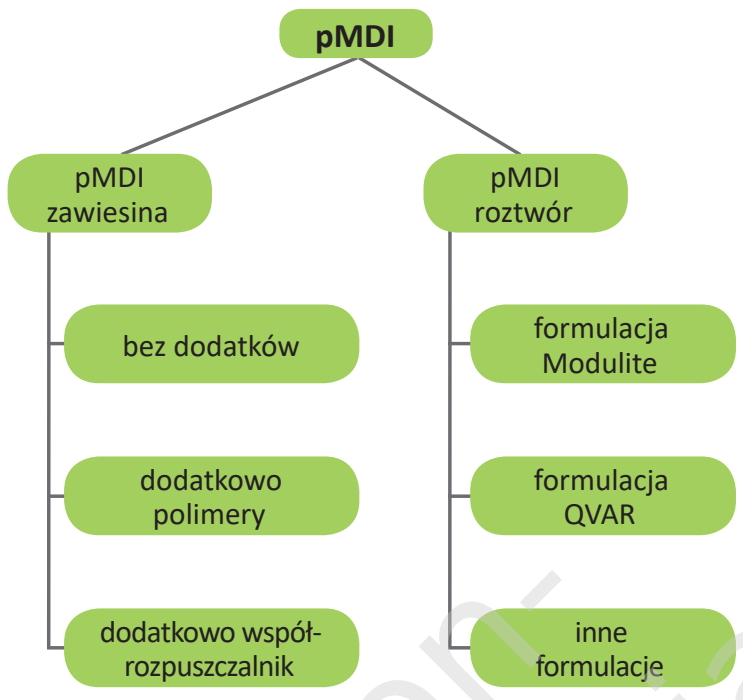

- zawiesina z dodatkowymi współrozpuszczalnikami, takimi jak etanol (w celu rozpuszczenia kwasu oleinowego w ilości wystarczającej do wytworzenia stabilnej zawiesiny) - np. furoinian mometazonu (FM) i FORM w preparacie Dulera ${ }^{\circledR}$ HFA 227a.

\section{Chmura aerozolowa leków z inhalatora ciśnienio- wego dozującego - rola komory inhalacyjnej}

Jakość chmury aerozolowej leku wyzwalanego z pMDI (m.in. wielkość cząstek, prędkość, kąt rozproszenia i zasięg) zależy od wielu elementów modyfikowalnych przez producenta leku i dostawcy inhalatora, takich jak [7, 14, 15]:

- formuła leku (zawiesina vs roztwór)

- stężenie leku

- wielkość cząstek (mikrokryształków) leku w przypadku zawiesiny

- surfaktant (rodzaj i ilość)

- współrozpuszczalniki (rodzaj i ilość)

- substancje smarujące (rodzaj)

- konstrukcja zaworu dozującego.

$\mathrm{W}$ populacji pediatrycznej, jak również u dorosłych zaleca się podawanie leku z pMDI za pomocą komory inhalacyjnej (KI) [8, 16-18]. Najważniejsze korzyści wynikające z zastosowania takiego połączenia to $[19,20]$ :

- brak potrzeby koordynacji między wdechem a wyzwoleniem leku z klasycznych pMDI

- zmniejszenie depozycji dużych cząstek aerozolu (>5 $\mu \mathrm{m}) \mathrm{w}$ jamie ustnej i gardle na skutek spowol- nienia chmury aerozolowej oraz zwiększenia odległości gardła od miejsca wyrzutu

- poprawa dystrybucji i depozycji aerozolu w dolnych drogach oddechowych

- możliwość prowadzenia skutecznej terapii inhalacyjnej w różnych grupach wiekowych, w tym u chorych niewspółpracujących lub zaintubowanych.

W przypadku zastosowania KI charakterystyka chmury aerozolowej docierającej do dróg oddechowych pacjenta ulega pewnym modyfikacjom. Większość badań wskazuje na poprawę parametrów chmury aerozolowej po dołączeniu KI do pMDI. Chmura aerozolowa opuszczająca KI ma mniejszą prędkość, mniejszą średnicę aerodynamiczną cząstki odpowiadającej medianie rozkładu masowego (MMAD, mass median aerodynamic diameter), większą frakcję cząstek drobnych (FPF, fine particle fraction), tj. udziału masowego w odsetku cząstek mniejszych od $5 \mu \mathrm{m}$, oraz porównywalne geometryczne odchylenie standardowe (GSD, geometric standard deviation) $\mathrm{z}$ chmurą aerozolową uwalnianą bezpośrednio z pMDI (ryc. 3) [21, 22]. Są to zatem zmiany korzystne z punktu widzenia efektywności terapii inhalacyjnej astmy czy POChP. Co ciekawe, dane wskazują, że wzrasta bezwzględna masa cząstek penetrujących do płuc (wyrażona jako udział dawki emitowanej substancji czynnej [ED, emitted dose]) mimo pewnych nieuniknionych strat leku osadzonego wewnątrz KI (ryc. 3).

KI nie są w pełni zamienne, ponieważ każda z wyróżniających je cech (objętość, kształt, liczba zastawek, tj. zaworów zwrotnych, materiał, z którego została wykonana) może wpływać na podaż leku i na jego efekt kliniczny. Na przykład zastosowanie KI typu AeroChamber Plus ${ }^{\circledR}$ pozwala na uzyskanie dwukrotnie większego stężenia propionianu flutykazonu w surowicy krwi (efekt biodostępności płucnej) w porównaniu z KI typu Babyhaler ${ }^{\circledR}$ [23]. W oparciu o tę oraz inne publikacje Europejska Agencja Leków (EMA, European Medicines Agency) zaleca, aby proces rejestracji leku z pMDI obejmował testowanie tych urządzeń w połączeniu z konkretną KI, której nazwa powinna zostać podana w charakterystyce danego produktu leczniczego [24-26].

Jak wspomniano wyżej, na chmurę aerozolową leku z pMDI wpływa wiele elementów mogących powodować duże różnice $\mathrm{w}$ jej charakterystyce. Te różnice zobrazowano w oparciu o wartość MMAD najczęściej stosowanych wGKS (tab. 1).

Niektóre leki w formulacji Modulite i QVAR (roztwory) są zaliczane do grupy superdrobnocząstko- 
Rycina 3. Porównanie chmury aerozolowej betametazonu uwalnianej bezpośrednio z pMDI oraz z pMDI w połaczeniu z komora inhalacyjna typu AeroChamber Plus ${ }^{\circledR}$. Opracowanie własne na podstawie danych z badania Williamsa RO $i$ wsp. [21].
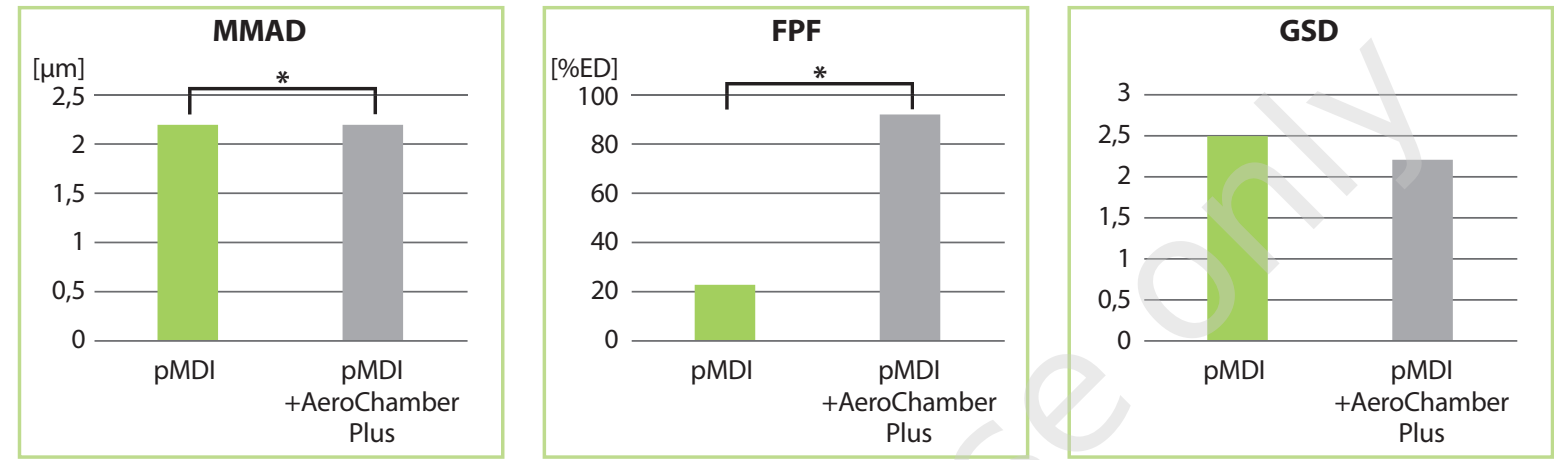

* $-\mathrm{p}<0,05$

ED (emitted dose) - dawka emitowana substancji czynnej; FPF (fine particle fraction) - frakcja cząstek drobnych; GSD (geometric standard deviation) - geometryczne odchylenie standardowe; MMAD (mass median aerodynamic diameter) - średnica aerodynamiczna cząstki odpowiadająca medianie rozkładu masowego.

Tabela 1. Wartość MMAD i wielkość depozycji płucnej różnych formulacji wGKS z pMDI HFA $134 a$ (badania $w$ warunkach optymalnego przeptywu i techniki inhalacji lub in vitro) (na podstawie [27-33]).

\begin{tabular}{|l|l|l|}
\multicolumn{1}{c|}{ Ginhalator/formulacja } & \multicolumn{1}{c|}{$(\mathbf{M m})$} & \multicolumn{1}{c|}{$\begin{array}{c}\text { Depozycja płucna } \\
\text { (\% dawki emitowanej) }\end{array}$} \\
\hline BDP - roztwór (Modulite) & $1,1-1,3$ & 56,0 \\
\hline BDP - roztwór (QVAR) & 1,1 & $51,0-68,0$ \\
\hline BUD - roztwór (Modulite) & ok. 3,5 & 18,5 \\
\hline Cyklezonid - roztwór & 1,1 & 52,0 \\
\hline Flunizolid - roztwór & 1,2 & $39,0-68,3$ \\
\hline PF-zawiesina & ok. 2,4 & 16,0 \\
\hline FM - zawiesina & bd & 13,9 \\
\hline Triamcynolon - roztwór & 4,5 & 26,0 \\
\hline
\end{tabular}

bd - brak danych; BDP - dwupropionian beklometazonu; BUD budezonid; FM - furoinian mometazonu; MMAD (mass median aerodynamic diameter) - średnica aerodynamiczna czastki odpowiadająca medianie rozkładu masowego; PF - propionian flutykazonu.

wych (MMAD - ok. 1,1 $\mu \mathrm{m})$ i cechują się dużą depozycją płucną [29, 34]. Pozostałe pMDIs tworzą aerozole o 2-4-krotnie większej wartości MMAD i stosunkowo małej depozycji płucnej $[27,28]$.

\section{Połączenia glikokorykosteroidów wziewnych} $z$ długo działającymi $\beta_{2}$-mimetykami $w$ inhalatorze ciśnieniowym dozującym - miejsce w terapii astmy

Różne połączenia wGKS z LABA w jednym inhalatorze są podstawą leczenia astmy $\mathrm{u}$ wielu chorych < 5. r.ż., na co wskazuje zarówno raport GINA 2021, jak i opracowanie Amerykańskiego Panelu Ekspertów $2020[18,35]$. W Europie i w Polsce jest popularny od wielu lat raport GINA, oparty na pięciostopniowym postępowaniu farmakologicznym u pacjentów w wieku $\geq 6$. r.ż. [18]. Według najnowszej wersji tego dokumentu terapia połączeniem wGKS + LABA jest postępowaniem preferowanym u chorych $\geq 12$. r.ż. na wszystkich stopniach leczenia, a u dzieci w wieku 6-11 lat od 3. do 5. stopnia [18]. Przy czym istnieją dwie ścieżki terapii wGSK + LABA:

- preferowana według modelu maintenance and reliever therapy (MART) z wykorzystaniem BUD lub BDP w połączeniu z FORM w jednym inhalatorze) oraz

- alternatywna (dawkowanie stałe) - wszystkie kombinacje wGKS + LABA w jednym inhalatorze lub ww. leki z dwóch różnych inhalatorów.

Kombinacja wGKS + LABA ma też określone miejsce w terapii POChP [36]. Obecnie dysponujemy kilkoma kombinacjami wGKS + LABA w DPI i pMDI. W tabeli 2 zestawiono kombinacje wGKS + LABA w pMDI dostępne w kraju (stan na 15.06.2021 r.).

Najdłużej na rynku znajduje się połączenie PF + SALM wprowadzone przed ok. 30 laty. Ta kombinacja z pMDI i z DPI oraz BUD + FORM z DPI są najlepiej przebadanymi połączeniami pod względem efektywności i bezpieczeństwa u chorych na astmę, w tym także u dzieci (tab. 3).

\section{Efektywność i koszty terapii z inhalatora ciśnieniowego dozującego vs inne urządzenia inhalacyjne}

Badania retrospektywne oraz prospektywne pokazały, że stosowanie 2-3 leków w jednym inhalatorze 
Tabela 2. Kombinacje GKS + LABA z pMDI zarejestrowane do leczenia astmy lub POChP dostepne w kraju (stan na 15.06.2021 r.) (wedtug ChPL; na podstawie [37-40]).

\begin{tabular}{|c|c|c|c|c|c|}
\hline $\begin{array}{c}\text { Kombinacja wGKS + } \\
\text { LABA }\end{array}$ & Formulacja & Dawkowanie & $\begin{array}{l}\text { Liczba dostępnych } \\
\text { preparatów }\end{array}$ & Wskazania & Wiek rejestracji \\
\hline $\mathrm{PF}+\mathrm{SALM}$ & zawiesina & stałe, 2 razy dziennie & 3 & astma & 24. r.ż. \\
\hline BUD + FORM & zawiesina & stałe, 2 razy dziennie & 1 & POChP & $\geq 18$. r.ż. \\
\hline$P F+F O R M$ & zawiesina & stałe, 2 razy dziennie & 1 & astma & $\geq$ 12. r.ż. \\
\hline BDP + FORM & roztwór & stałe i MART & 1 & astma, POChP & > 18. r.ż. \\
\hline
\end{tabular}

BDP - dwupropionian beklometazonu; BUD - budezonid; FORM - formoterol; LABA (long-acting $\beta_{2}$-agonist) - długo działający $\beta_{2}$-mimetyk; MART (maintenance and reliever therapy) - terapia podtrzymująca i łagodząca; PF - propionian flutykazonu; POChP - przewlekła obturacyjna choroba płuc; SALM - salmeterol; wGKS - glikokortykosteroid wziewny.

Tabela 3. Liczba publikacji z bazy PubMed dotyczaca połaczeń PF + SALM, BUD + FORM, FP + FORMi beklometazon (BDP) + FORM (stan na 15.06.2021 r.).

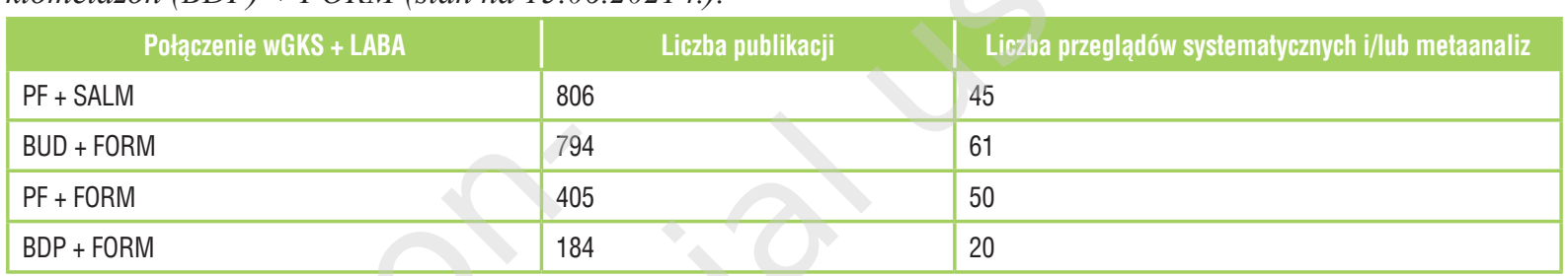

BDP - dwupropionian beklometazonu; BUD - budezonid; FORM - formoterol; LABA (long-acting $\beta_{2}$-agonist) - długo działający $\beta_{2}$-mimetyk; PF - propionian flutykazonu; SALM - salmeterol; wGKS - glikokortykosteroid wziewny.

wiąże się z mniejszym wykorzystaniem zasobów opieki zdrowotnej i lepszą opłacalnością w porównaniu ze stosowaniem tych samych leków z 2-3 inhalatorów [41]. Takie postępowanie poprawia także adherencję do zalecanej terapii, pacjenci generują mniej błędów, a leczenie jest co najmniej tak samo efektywne jak w przypadku stosowania leków z 2-3 różnych inhalatorów [42-44]. Wykazano też, iż terapia astmy za pomocą leków z pMDI jest tańsza vs pMDI-BA i DPI, przy porównywalnej efektywności klinicznej [45-47]. Choć nowsze DPI mogą poprawiać satysfakcję chorych z leczenia inhalacyjnego, nie mają istotnie większej efektywności klinicznej vs starsze DPI i pMDI [48]. Z kolei w dużym badaniu retrospektywnym u pacjentów z POChP, u których zastosowano terapię lekami z pMDI vs leki z DPI, stwierdzono, że leczenie z pMDI to [49]:

- $10 \%$ niższe koszty wszystkich procedur medycznych (2673 vs 2956 dol.)

- $19 \%$ niższe koszty związane z POChP (przewidywane średnie koszty: 138 vs 169 dol.)

- $28 \%$ mniejsze prawdopodobieństwo ponownej hospitalizacji związanej $\mathrm{z}$ zaostrzeniem POChP w ciągu 60 dni po wypisie.

Wyniki te wymagają jednak potwierdzenia w badaniach prospektywnych przeprowadzonych w odpowiednio dobranych grupach chorych.

Na koniec kilka uwag dotyczących efektywności i kosztów terapii pMDI vs nebulizacja. Najwięcej danych dotyczy dzieci z astmą, a szerokie opracowanie tego problemu w piśmiennictwie krajowym ukazało się w 2020 r. [50]. W oparciu o dostępne dane z kilku krajów (USA, Kanada, Nowa Zelandia, Izrael, Singapur) wykazano, że leczenie SABA za pomocą pMDI + KI to:

- terapia efektywniejsza (poprawa parametrów klinicznych i/lub poprawa funkcji płuc) niż nebulizacja (szczególnie w grupie dzieci 0-2 lata)

- krótszy czas pobytu na SOR i mniejsze ryzyko hospitalizacji niż w przypadku SABA w nebulizacji

- większe bezpieczeństwo oceniane głównie za pomocą parametrów klinicznych vs nebulizacja

- znacznie niższe koszty niż w przypadku nebulizacji zarówno w warunkach SOR, jak i oddziału szpitalnego.

Wyniki badań własnych wskazują, iż w leczeniu szpitalnym dzieci z zaostrzeniem astmy podanie leku z pMDI + KI generuje o 1,5-2,5 razy niższe koszty niż w przypadku nebulizacji, bez względu na rodzaj leku antyobturacyjnego i typ użytej KI [51].

\section{Kiedy wybrać inhalator ciśnieniowy dozujący dla dzieci i dorosłych?}

W pMDI jest dostępna większość klas leków stosowanych w terapii astmy lub POChP - brak jedynie długo działającego leku przeciwcholinolitycznego 
(LAMA, long-acting muscarinic antagonists) oraz kombinacji LABA + LAMA (tab. 4).

Tabela 4. Klasy leków dostepnych w pMDI lub pMDI-BA w kraju (stan na 15.06.2021 r.).

\begin{tabular}{|l|l|l|l|}
\multicolumn{1}{c|}{ Klasa lekII } & \multicolumn{1}{c|}{ pMIDI } & \multicolumn{1}{c|}{ Razem } \\
\hline WGKS & 4 & 1 & 5 \\
\hline LABA & 2 & 0 & 2 \\
\hline WGKS + LABA & 3 & 0 & 3 \\
\hline SABA & 2 & 1 & 3 \\
\hline SAMA & 1 & 0 & 1 \\
\hline SABA + SAMA & 1 & 0 & 1 \\
\hline LAMA & 0 & 0 & 0 \\
\hline LABA + LAMA & 0 & 0 & 0 \\
\hline GKS + LABA + LAMA & 1 & 0 & 1 \\
\hline Razem & $\mathbf{1 4}$ & $\mathbf{2}$ & $\mathbf{1 6}$ \\
\hline
\end{tabular}

GKS - glikokortykosteroid; pMDI - inhalator ciśnieniowy dozujący; pMDI-BA; LABA (long-acting $\beta_{2}$-agonist) - długo działający $\beta_{2}$-mimetyk; LAMA (long-acting muscarinic antagonists) - długo działający lek przeciwcholinolityczny; SABA (short-acting $\beta_{2}$-agonists) - krótko działający $\beta_{2}$-mimetyk; SAMA (short-acting muscarinic antagonist) krótko działający lek przeciwcholinolityczny; wGKS - glikokortykosteroid wziewny.

Ponadto w USA jest używana kombinacja formoterolu $\mathrm{z}$ glikopironium $\mathrm{w}$ oryginalnej formulacji (co-suspension delivery technology, preparat Bevespi Aerosphere $^{\circledR}$ ) u pacjentów z POChP [52].

Inhalator ciśnieniowy dozujący może być pierwszym wyborem pośród innych inhalatorów w następujących przypadkach [8, 53-57]:

- chory ma naturalną tendencję do powolnego oddychania (a nie do szybkiego i głębokiego)

- pacjent osiąga suboptymalny szczytowy przepływ wdechowy dla danego DPI (zazwyczaj $<30-40$ $1 / \mathrm{min})$

- chory na POChP umiarkowane/ciężkie (3-4 stopnie według GOLD) z towarzyszącymi zaburzeniami poznawczymi, narządu ruchu itp. - zawsze z KI

- pacjent $\mathrm{z}$ astmą umiarkowaną/ciężką z zaburzeniami w drobnych oskrzelach (szczególnie wtedy pMDI $z$ formulacją superdrobnocząstkową)

- dziecko z astmą < 6. r.ż. (pMDI + KI, wyjątek Dysk $^{\circledR} \mathrm{i}$ inhalatory dyskopodobne: $\mathrm{G} 7^{\circledR}$, Aerostar $^{\circledR}$ )

- lek lub kombinacje leków są dostępne tylko w pMDI

- chory nie toleruje DPI (laktozy lub formulacji proszkowej leku)

- chory ma trudności z techniką używania DPI

- ważny jest efekt ekonomiczny (pMDI + KI są efektywniejsze i tańsze od nebulizacji w przypadku SABA, SAMA, wGKS).

\section{Podsumowanie}

Klasyczny inhalator ciśnieniowy dozujący wymaga koordynacji pomiędzy uwolnieniem odmierzonej dawki leku a wdechem chorego, co nie dotyczy pMDI aktywowanego wdechem. Leki z klasycznych pMDI powinny być inhalowane za pomoca odpowiednich komór inhalacyjnych, co zapewnia z reguły większą skuteczność i bezpieczeństwo terapii. Leki w pMDI występują w dwóch głównych formulacjach - jako roztwory i jako zawiesiny. To przekłada się na charakter produkowanej chmury aerozolowej i wielkość depozycji płucnej inhalowanych leków. Inhalator ciśnieniowy dozujący jest jedynym obok nebulizacji urządzeniem inhalacyjnym do stosowania u dzieci $<4$. r.ż. i pierwszym wyborem w leczeniu astmy dzieci $<6$. r.ż. Jest także zalecanym inhalatorem dla pacjentów z astmą czy POChP z suboptymalnym szczytowym przepływem wdechowym, niezależnie od wieku. Połączenie wGKS + LABA w jednym inhalatorze pozostaje od wielu lat podstawą farmakoterapii astmy $\mathrm{u}$ wielu chorych $>$ 5. r.ż. Terapia astmy czy POChP lekami z pMDI jest tańsza niż w przypadku DPI czy nebulizacji, przy zachowaniu podobnej efektywności klinicznej.

\section{Piśmiennictwo}

1. Dane z Farmaceutycznej Bazy Danych, IQVIA 2021 sell in.

2. Sanders M. Inhalation therapy: a historical review. Prim Care Respir J. 2007; 16(2): 71-81.

3. Stein SW, Charles G. Thiel ChG. The history of therapeutic aerosols: a chronological review. J Aerosol Med Pulm Drug Deliv. 2017; 30(1): 20-41.

4. Sosnowski TR. Zasada działania i konstrukcja inhalatorów medycznych. In: Sosnowski TR (ed). Aerozole wziewne i inhalatory. $2^{\text {nd }}$ ed suppl. Politechnika Warszawska - Wydziat Inżynierii Chemicznej i Procesowej, Warszawa 2012: 73-124.

5. Newman SP. Principles of metered-dose inhaler design. Respir Care. 2005; 50(9): 1177-90.

6. Ibiapina CC, Cruz AA, Camargos PMA [Hydrofluoroalkane as a propellant for pressurized metered-dose inhalers: history, pulmonary deposition, pharmacokinetics, efficacy and safety]. J Pediatr (Rio J). 2004; 80(6): 441-6.

7. Stein SW, Sheth P, Hodson PD et al. Advances in metered dose inhaler technology: hardware development. AAPS Pharm Sci Tech. 2014; 15(2): 326-38.

8. Emeryk A, Pirożyński M, Mazurek H et al. Polski przewodnik inhalacyjny. $2^{\text {nd }}$ ed. Via Medica, Gdańsk 2021: 1-33.

9. Newman SP, Weisz AW, Talaee $N$ et al. Improvement of drug delivery with a breath actuated pressurized aerosol for patients with poor inhaler technique. Thorax. 1991; 46(10): 712-6. 
10. https://www.accessdata.fda.gov/drugsatfda_docs/label/ 2012/020911s022lbl.pdf (access: 18.06.2021).

11. Lechuga-Ballesteros D, Noga B, Vehring $R$ et al. Novel cosuspension metered-dose inhalers for the combination therapy of chronic obstructive pulmonary disease and asthma. Futur Med Chem. 2011; 3: 1703-18.

12. Sukasamea N, Boonmea P, Srichanaa T. Development of budesonide suspensions for use in an HFA pressurized metered dose inhaler. Science Asia. 2011; 37: 31-7.

13. Rogueda P. Novel hydrofluoroalkane suspension formulations for respiratory drug delivery. Expert Opin Drug Deliv. 2005; 2(4): $625-38$.

14. De Vries TW, Rottier BL, Gjaltema D. Comparative in vitro evaluation of four corticosteroid metered dose inhalers: consistency of delivered dose and particle size distribution. Respir Med. 2009; 103(8): 1167-73.

15. Schroeter JD, Sheth P, Hickey AJ. Effects of formulation variables on lung dosimetry of albuterol sulfate suspension and beclomethasone dipropionate solution metered dose inhalers. AAPS PharmSciTech. 2018; 19: 2335-45.

16. Emeryk A, Doniec Z, Mazurek $H$ et al. Guidelines for inhalation chambers in children. Ped Pol. 2017; 92: 288-93.

17. Vincken W, Levy ML, Scullion J et al. Spacer devices for inhaled therapy: why use them, and how? ERJ Open Res. 2018; 4: 00065-2018.

18. GINA 2021 Report, Global Strategy for Asthma Management and Prevention. https://ginasthma.org/gina-reports (access: 25.04.2021).

19. Ammari WG, Oriquat GA, Sanders M. Comparative pharmacokinetics of salbutamol inhaled from a pressurized metered dose inhaler either alone or connected to a newly enhanced spacer design. Eur J Pharm Sci. 2020; 147: 105304.

20. Nikander $K$, Nicholls $C$, Denyer J et al. The evolution of spacers and valved holding chambers. J Aerosol Med Pulm Drug Deliv. 2014; 27(suppl 1): S4-S23.

21. Williams RO, Patel AM, Barron MK et al. Investigation of some commercially available spacer devices for the delivery of glucocorticoid steroids from a pMDI. Drug Dev Ind Pharm. 2001; 27(5): 401-12.

22. Saeed H, Abdelrahim ME, Rabea $H$ et al. Evaluation of disposable and traditional accessory devices for use with a pressurized metered-dose inhaler. Respir Care. 2020; 65(3): 320-5.

23. Blake K, Mehta R, Spencer T et al. Bioavailability of inhaled fluticasone propionate via chambers/masks in young children. Eur Respir J. 2012; 39(1): 97-103.

24. Dissanayake S. Application of the EU Guidelines for pharmacokinetic studies of locally acting orally inhaled drug products. Respir Drug Deliv. 2010; 1: 293-304.

25. Lavorini F, Barreto C, van Boven JFM et al. Spacers and valved holding chambers - the risk of switching to different chambers. J Allergy Clin Immunol Pract. 2020; 8(5): 1569-73.
26. Dissanayake S, Suggest J. A review of the in vitro and in vivo valved holding chamber (VHC) literature with a focus on the AeroChamber Plus Flow-Vu Anti-static VHC. Ther Adv Respir Dis. 2018; 12: 1-14.

27. Martin RJ. Therapeutic significance of distal airway inflammation in asthma. J Allergy Clin Immunol. 2002; 109(2 suppl): S447-S60.

28. Zeidler M, Corren J. Hydrofluoroalkane formulations of inhaled corticosteroids for the treatment of asthma. Treat Respir Med. 2004; 3(1): 35-44.

29. Leach ChL. The CFC to HFA transition and its impact on pulmonary drug development. Respir Care. 2005; 50(9): 1201-6.

30. Emeryk A. Glikokortykosteroidy $w$ astmie. In: Emeryk A, Bręborowicz A, Lis G et al (ed). Astma i choroby obturacyjne oskrzeli u dzieci. Elsevier Urban \& Partner, Wroctaw 2010: 121-44.

31. Hirst PH, Pitcairn GR, Richards JC et al. Deposition and pharmacokinetics of an HFA formulation of triamcinolone acetonide delivered by pressurized metered dose inhaler. J Aerosol Med. 2001; 14(2): 155-65.

32. Pickering H, Pitcairn GR, Hirst PH et al. Regional lung deposition of a technetium $99 \mathrm{~m}$-labeled formulation of mometasone furoate administered by hydrofluoroalkane 227 metered-dose inhaler. Clin Ther. 2001; 22(12): 1483-93.

33. Frazer PA. Assessment of aerodynamic particle size distribution of BDP BAI and QVAR MDI. Data on file ( $R \& D$ Investigation Report). Teva Respiratory, LLC. 2017 (access: 16.06.2021)

34. Vanden Burgt JA, Busse WW, Martin RJ et al. Efficacy and safety overview of a new inhaled corticosteroid, QVAR (hydrofluoroalkane-beclomethasone extrafine inhalation aerosol) in asthma. J Allergy Clin Immunol. 2000; 106: 1209-26.

35. Cloutier MM, Baptist AP, Blake KV et al; NAEPPCC Expert Panel Working Group. 2020 Focused Updates to the Asthma Management Guidelines: A Report from the National Asthma Education and Prevention Program Coordinating Committee Expert Panel Working Group. JACI. 2020; 146(6): 1217-70.

36. 2021 GOLD Reports. Global Strategy for Prevention, Diagnosis and Management of COPD. https://goldcopd.org/ 2021-gold-reports (access: 15.06.2021).

37. http://leki.urpl.gov.pl/files/25_Fostex_aeroz_inhal.pdf (access: 15.06.2021).

38. http://leki.urpl.gov.pl/files/34_Comboterol_aerozol_zawiesina_25_125mg_25_250mg.pdf (access: 15.06.2021).

39. https://www.mp.pl/pacjent/leki/subst.html?id=3741 (access: 15.06.2021).

40. http://leki.urpl.gov.pl/files/25_Seretide_50_125_250_zaw.pdf (access: 15.06.2021).

41. Zhang S, King D, Rosen VM et al. Impact of single combination inhaler versus multiple inhalers to deliver the same medications for patients with asthma or COPD: a systematic literature review. Inter J COPD. 2020; 15: 417-38. 
42. Bosnic-Anticevich S, Chrystyn H, Costello RW et al. The use of multiple respiratory inhalers requiring different inhalation techniques has an adverse effect on COPD outcomes. Int J Chron Obstruct Pulmon Dis. 2017; 12: 59-71.

43. Price D, Chrystyn H, Kaplan A et al. Effectiveness of same versus mixed asthma inhaler devices: a retrospective observational study in primary care. Allergy Asthma Immunol Res. 2012; 49(4): 184-91.

44. Usmani OS, Hickey AJ, Guranlioglu F et al. The impact of inhaler device regimen in patients with asthma or COPD. J Allergy Clin Immunol Pract. 2021; S2213-2198(21)00464-5.

45. Masayuki Hojo M, Shirai T, Hirashima J. Comparison of the clinical effects of combined salmeterol/fluticasone delivered by dry powder or pressurized metered dose inhaler. Pulm Pharmacol Ther. 2016; 37: 43-8.

46. Morice AH, Hochmuth L, Ekelund J et al. Comparable longterm safety and efficacy of a novel budesonide/formoterol pressurized metered-dose inhaler versus budesonide/formoterol Turbuhaler in adolescents and adults with asthma. Pulm Pharmacol Ther. 2008; 21(1): 32-9.

47. Kemp L, Haughney J, Barnes $N$ et al. Cost-effectiveness analysis of corticosteroid inhaler devices in primary care asthma management: A real world observational study. Clinicoecon Outcomes Res. 2010; 2: 75-85.

48. Ninane V, Vandevoorde J, Cataldo D et al. New developments in inhaler devices within pharmaceutical companies: a systematic review of the impact on clinical outcomes and patient preferences. Respir Med. 2015; 109(11): 1430-8.

49. Wittbrodt ET, Millette LA, Evans KA et al. Differences in health care outcomes between postdischarge COPD patients treated with inhaled corticosteroid/long-acting $\beta 2$-agonist via dry-powder inhalers and pressurized metered dose inhalers. Inter J Chron Obstruct Pulmon Dis. 2019; 14: 101-14.

50. Emeryk A, Janeczek K, Emeryk-Maksymiuk J. Leki z inhalatora ciśnieniowego dozującego z użyciem komory inhalacyjnej czy z nebulizatora? Co jest efektywniejsze, bezpieczniejsze i tańsze w terapii astmy u dzieci? Terapia. 2020; 4(387): 93-99.

51. Janeczek K, Emeryk A, Bodajko-Grochowska A et al. A comparison of the costs of bronchodilator delivery methods in children with asthma exacerbations treated in hospital. The first Polish study in children. Adv Dermatol Allergol. 2020; 37: 1-6.

52. Self TH, Ellingson S. New treatment option for chronic obstructive pulmonary disease: two long-acting bronchodilators in a single metered-dose inhaler. Am J Med. 2017; 130(11): 1251-4.

53. Haidl P, Heindl S, Siemon K. Inhalation device requirements for patients' inhalation maneuvers. Respir Med. 2016; 118: 65-75.

54. Usmani OS. Choosing the right inhaler for your asthma or COPD patient. Ther Clin Risk Manag. 2019; 15: 461-72.

55. Mahler DA. The role of inspiratory flow in selection and use of inhaled therapy for patients with chronic obstructive pulmonary disease. Respir Med. 2020; 161: 105857.

56. Fuglo-Mortensen R, Lange P, Mortensen J. [Inhalers and inhalation techniques in the treatment of asthma and chronic obstructive pulmonary disease]. Ugeskr Laeger. 2019; 181(33): 5-9.

57. Rogliani P, Calzetta L, Coppola A et al. Optimizing drug delivery in COPD: the role of inhaler devices. Respir Med. 2017; 124: 6-14

ORCID

A. Emeryk - ID - http://orcid.org/0000-0003-1853-8696

K. Janeczek - ID - http://orcid.org/0000-0002-8163-873x

T.R. Sosnowski - ID - http://orcid.org/0000-0002-6775-3766

J. Emeryk-Maksymiuk - ID - http://orcid.org/0000-0003-2709-0424

Wkład autorów/Authors' contributions:

A. Emeryk: koncepcja pracy, przygotowanie manuskryptu; K. Janeczek: redakcja podrozdziału o komorach inhalacyjnych, korekta manuskryptu; T.R. Sosnowski: podrozdział o pMDI, korekta manuskryptu; J. Emeryk-Maksymiuk: przygotowanie podrozdziału o wyborze pMDI dla dzieci i dorosłych, korekta manuskryptu.

Konflikt interesów/Conflict of interests:

Nie występuje.

Finansowanie/Financial support:

Nie występuje.

Etyka/Ethics:

Treści przedstawione w artykule są zgodne z zasadami Deklaracji Helsińskiej, dyrektywami EU oraz ujednoliconymi wymaganiami dla czasopism biomedycznych.

Copyright: (C) Medical Education sp. z 0.0. This is an Open Access article distributed under the terms of the Attribution-NonCommercial 4.0 International (CC BY-NC 4.0). License (https://creativecommons.org/licenses/by-nc/4.0/), allowing third parties to copy and redistribute the material in any medium or format and to remix, transform, and build upon the material, provided the original work is properly cited and states its license.

Adres do korespondencji

\section{prof. dr hab. n. med. Andrzej Emeryk}

Klinika Chorób Płuc i Reumatologii Dziecięcej,

Uniwersytet Medyczny w Lublinie,

Uniwersytecki Szpital Dziecięcy w Lublinie

20-093 Lublin, ul. prof. Antoniego Gębali 6

tel.: (81) 7185477

e-mail: emerykandrzej@gmail.com 